\title{
Correction to: Feature selection and risk prediction for patients with coronary artery disease using data mining
}

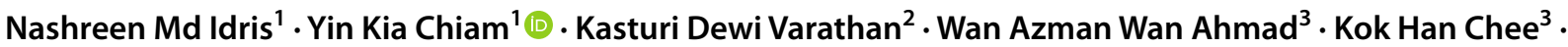 \\ Yih Miin Liew ${ }^{4}$
}

Published online: 19 January 2022

(C) International Federation for Medical and Biological Engineering 2022

\section{Correction to: Medical \& Biological Engineering \& Computing (2020) 58:3123-3140 https://doi.org/10.1007/s11517-020-02268-9}

Acknowledgments should be presented as below:

Acknowledgments This research was funded by the Ministry of Higher Education Malaysia (MOHE)'s Fundamental Research Grant Scheme (FRGS), Project Code: FRGS/1/2017/ICT01/UM/02/4. The authors would like to thank the Governance Board member of the Malaysian National Cardiovascular Disease Database (NCVD) Registry for providing us with the Acute Coronary Syndrome (ACS) dataset to be used for the research.
Acknowledgement also goes to the Ministry of Health Malaysia and National Heart Association of Malaysia for funding the NCVD Registry database. Thanks to all the NCVD investigators and to all source data providers for their contribution to this registry.

Publisher's note Springer Nature remains neutral with regard to jurisdictional claims in published maps and institutional affiliations.

The online version of the original article can be found at https:// doi.org/10.1007/s11517-020-02268-9

Yin Kia Chiam

yinkia@um.edu.my

1 Department of Software Engineering, Faculty of Computer Science and Information Technology, Universiti Malaya, 50603 Kuala Lumpur, Malaysia

2 Department of Information Systems, Faculty of Computer Science and Information Technology, Universiti Malaya, 50603 Kuala Lumpur, Malaysia

3 Department of Medicine, University Malaya Medical Centre, 50603 Kuala Lumpur, Malaysia

4 Department of Biomedical Engineering, Faculty of Engineering, Universiti Malaya, 50603 Kuala Lumpur, Malaysia 